\title{
The ABO and Rhesus blood groups in Perthes' disease
}

\author{
J. MALCOLM CAMERON ${ }^{1}$ AND MARIAN M. IZATT \\ From the University Department of Orthopaedics, Western Infirmary, the Royal \\ Hospital for Sick Children, Glasgow, and the Glasgow and West \\ of Scotland Regional Blood Transfusion Service
}

SYNOPSIS Determinations were carried out of the ABO blood groups and Rhesus phenotypes of a series of 142 children with Perthes' disease. Where possible their parents and sibs were also grouped. Sera from the mothers of affected children were examined for the presence of Rhesus antibodies.

No apparent association was demonstrated between Perthes' disease and any ABO phenotype. The disease is also apparently independent of $\mathrm{ABO}$ incompatibility between mother and child.

There is the suggestion in these families of an increased incidence of the Rhesus cc phenotype among the affected children. The level of significance is estimated at $0 \cdot 02$, even after taking into account the numerous significance tests possible on the data.

Parental and sibship studies show that any association between Perthes' disease and the Rhesus Cc phenotypes, if one does exist, is unlikely to be the product of genetical stratification within the population.

Maternal Rhesus antibody, acting through the agency of haemolytic disease of the newborn, plays no detectable part in the aetiology of a subsequently developing Perthes' disease in the child.

The aetiology of Perthes' disease, described simultaneously in 1909-10 by Legg, Calvé, Perthes, and Waldenström, is still obscure (Goff, Shutkin, and Hersey, 1954). The condition consists essentially of degenerative changes in the femoral head during childhood, resulting in flattening and irregular rarefaction of the upper femoral capital epiphysis (Jonsäter, 1953). It may be bilateral but is more commonly unilateral and boys are affected more frequently than girls. In a series of 142 cases, Cameron and Izatt (1960) found the ratio of boys to girls to be 4.3 to 1 . It was also found that the birth position of the affected children in their sibships was of no significance, and that the children did not differ appreciably in height and weight from unaffected children. During the noting of case histories it was observed that many mothers volunteered the information that their children were jaundiced at birth. In the earlier communication (Cameron and Izatt, 1960) the results of ABO and Rhesus D blood group studies in the 142 affected children were given.

Received for publication 29 May 1961.

'Present address: Department of Pathology, Southern General Hospital, Glasgow.

'Present address: Department of Genetics, University of Glasgow.
It is the purpose of this paper to report in more detail an investigation into the possibility of a relationship between a blood group incompatibility between the mother and child, and the subsequent development of Perthes' disease in the child. Though we were particularly interested in examining the maternal sera for the presence of immune Rhesus antibodies, it was felt that much valuable information could be obtained by grouping entire families, the father and sibs as well as the affected children and their mothers. Wansbrough, Carrie, Walker, and Ruckerbauer (1959) had suggested, and our findings (Cameron and Izatt, 1960) are in agreement, that the disease is inherited and based on a sex-influenced autosomal dominant gene with low penetrance and varying expression.

\section{MATERIAL}

A series of 185 children with apparently unequivocal Perthes' disease was available for study, but a blood sample could only be obtained from the affected propositus in 142 families. The measure of our success in tracing every member of these $\mathbf{1 4 2}$ families is recorded in Table I. Out of a total of 832 persons, 700 were blood grouped. Of the missing 132, 40 are dead, 16 no longer 
TABLE I

DETAILS OF FAMILIES TESTED

832 Persons in 142 Families

700 persons grouped $\begin{cases}\text { propositi } & 142 \\ \text { their mothers } & 133 \\ \text { their fathers } & 116 \\ \text { their sibs } & 309\end{cases}$

live in the Glasgow area, and 76 either refused to allow us to group them, or they were unobtainable for other reasons. For example, one affected boy is an adopted child and his parents are unknown; a husband refused to allow us to approach his wife from whom he is separated.

Only one family had more than one child with Perthes' disease, a brother and sister being affected. In all calculations the groups of the boy alone, the propositus, are included in the total of affected children. The series also includes two affected children who are first cousins, but otherwise the families are believed to be unrelated.

All families were followed up with equal diligence in an attempt to exclude preferential investigation of those in which some individuals already knew their blood groups. It is difficult to estimate the extent to which families cooperated wholeheartedly with us because of awareness that a relative is Rhesus negative. As will be seen later from study of the distribution of the parental Rhesus D groups, there is no evidence that a significant bias of this nature had been operating. The source and adequacy of control series will be discussed in more detail in the text to follow.

\section{TECHNICAL METHODS}

ABO GROUPING TESTS AT ROOM TEMPERATURE The ABO group of the red cells of each specimen was determined by using anti-A, anti-B, and the combined anti-A $+B$ of a group $O$ serum shown to be capable of detecting the lower subgroups of $A$, such as $A_{x}$. As confirmation of the red cell ABO grouping results, the serum from each specimen was tested with known group A and group B cells to detect the presence or absence of the appropriate natural agglutinins, anti-A and anti-B.

RHESUS TESTING AT $37^{\circ} \mathrm{C}$. All specimens were tested with a panel of Rhesus antisera: an anti-C $+\mathbf{C w}$, an anti-c, 2 anti-D, and an anti-E. For consistency of resu倞s single batches of these antisera were used throughout the investigation.

ANTIBODY SCREENING TESTS AT $37^{\circ} \mathrm{C}$. The sera from specimens were screened with $R_{1} R_{2}$ (CDe/cDE) and $\bar{c} r$ (cde/cde) cells, which had been trypsinized to renfer them more sensitive in detecting Rhesus antibodies. Sera positive in screening tests were examined furtherg\%o confirm the presence of, and to identify any antibody contained in them. Such sera were tested by salifie, albumin, and indirect antiglobulin techniques against $\vec{t}$ comprehensive panel of group $\mathbf{O}$ cells of varying Rhesits phenotype (CcDe, CDe, CcDE, cDE, Cde, cdE, cde).

COMPATIBILITY TESTING AT $37^{\circ} \mathrm{C}$. Maternal serum velas tested in saline, albumin, and by indirect antiglobulin tests for compatibility with the red cells of husband a $\overrightarrow{a d}$ children.

\section{RESULTS AND DISCUSSION}

ABO GROUPING TESTS There is no apparent relationship between the $\mathrm{ABO}$ blood groups and the occurrence of Perthes' disease in children. For reasoss discussed in detail in our earlier paper, we used, fin compiling control series, the data from 5,898 colfsecutive new donor registrations with the West 8 f Scotland Regional Blood Transfusion Service.Tale II records the incidence of the ABO groups within the series of affected children and their parents. FBr all three classes there is no significant differente between the observed ABO group distributions amd those of the control series. Because of the relatively small numbers involved, group $\mathbf{A B}$ and group $\$$ individuals were classed together in these calcutiotions.

RHESUS TESTING Phenotyping with anti-C + anti-c, anti-D, and anti-E enabled data to be compiled regarding the Rhesus phenotype distributions in this series of families in which a child is affected by Perthes' disease (Table III). In the calculations comparing these distribution figures with a random

TABLE II

ABO BLOOD GROUP DISTRIBUTION

\begin{tabular}{|c|c|c|c|c|}
\hline Group & $\begin{array}{l}\text { Control Series of } \\
\text { Random Donors }\end{array}$ & $\begin{array}{l}\text { No. of Affected } \\
\text { Children }\end{array}$ & $\begin{array}{l}\text { No. of Mothers of } \\
\text { Affected Children }\end{array}$ & $\begin{array}{l}\text { No. of Fathers of } \\
\text { Affected Children }\end{array}$ \\
\hline $\begin{array}{l}\mathbf{A B} \\
\mathbf{A} \\
\mathbf{B} \\
\mathbf{0}\end{array}$ & $\begin{array}{c}178(3.02 \%) \\
1,906(32.31 \%) \\
637(10.80 \%) \\
3,177(53.88 \%)\end{array}$ & $\begin{array}{c}4(2.82 \%) \\
50(35.22 \%) \\
15(10.56 \%) \\
73(51.40 \%)\end{array}$ & $\begin{array}{c}6(4.57 \%) \\
49(36 \cdot 84 \%) \\
14(10 \cdot 52 \%) \\
64(48 \cdot 12 \%)\end{array}$ & $\begin{array}{c}4(3.45 \%) \\
40(34.48 \%) \\
9(7 \cdot 76 \%) \\
63(54.30 \%)\end{array}$ \\
\hline Total & 5,898 & 142 & 133 & 116 \\
\hline
\end{tabular}

Combining groups $\mathbf{A B}$ and $\mathbf{B}$.

Affected children, $x^{2}=0.54$, d.f. $=2,0.8>P>0.7$.

Mothers of affected children, $x^{2}=1 \cdot 76$, d.f. $=2,0.5>P>0.3$.

Fathers of affected children, $x^{2}=0.73$, d.f. $=2,0.7>P>0.5$. 
TABLE III

RHESUS PHENOTYPE DISTRIBUTION

\begin{tabular}{|c|c|c|c|c|c|}
\hline Antigens $^{1}$ & $\begin{array}{l}\text { Principal Genotypes } \\
\text { Deduced to be Included }\end{array}$ & Control Series 2 & $\begin{array}{l}\text { No. of Affected } \\
\text { Children }\end{array}$ & $\begin{array}{l}\text { No. of Mothers of } \\
\text { Affected Children }\end{array}$ & $\begin{array}{l}\text { No. of Fathers of } \\
\text { Affected Children }\end{array}$ \\
\hline $\mathrm{CcDe}$ & $\begin{array}{l}\text { CDe/cde }\left(\mathbf{R}_{1} r\right) \\
\text { CDe/cDe }\left(\mathbf{R}_{1} \mathbf{R}_{0}\right)\end{array}$ & $1,690(36.49 \%)$ & $41(28.87 \%)$ & $48(36.09 \%)$ & $34(29 \cdot 31 \%)$ \\
\hline CDe & $\begin{array}{l}\text { CDe/CDe }\left(\mathbf{R}_{1} \mathbf{R}_{1}\right) \\
\text { CDe/Cde }\left(\mathbf{R}_{1} \mathbf{R}^{\prime}\right)\end{array}$ & $795(17 \cdot 16 \%)$ & $19(13.39 \%)$ & $17(12 \cdot 78 \%)$ & $12(10.34 \%)$ \\
\hline CcDE & $\begin{array}{l}\text { CDe/cDE }\left(R_{1} R_{2}\right) \\
\text { CDE/cde }\left(R_{2} r\right) \\
\text { cDE/cde }\left(R_{2} r\right)\end{array}$ & $639(13.79 \%)$ & $16(11 \cdot 27 \%)$ & $21(15.79 \%)$ & $20(17 \cdot 24 \%)$ \\
\hline cDE & $\begin{array}{l}\text { cDE/cDE }\left(\mathbf{R}_{2} R_{2}\right) \\
\text { cDE/cDe }\left(R_{2} R_{0}\right)\end{array}$ & $655(14 \cdot 14 \%)$ & $27(19.01 \%)$ & $18(13.53 \%)$ & $22(18.97 \%)$ \\
\hline $\begin{array}{l}\text { cDe } \\
\text { Ccde } \\
\text { cdE } \\
\text { cde }\end{array}$ & $\begin{array}{l}\text { cDe/cde (Ror) } \\
\text { Cde/cde (R'r) } \\
\text { cdE/cde (R'r) } \\
\text { cde/cde (rr) }\end{array}$ & $\begin{array}{c}58(1.25 \%) \\
25(0.54 \%) \\
18(0.39 \%) \\
752(16.23 \%)\end{array}$ & $\begin{array}{l}3(2.11 \%) \\
1(0.70 \%) \\
35(24.65 \%)\end{array}$ & $\begin{array}{c}1(0 \cdot 75 \%) \\
1(0 \cdot 75 \%) \\
27(20 \cdot 30 \%)\end{array}$ & $\begin{array}{c}3(2.59 \%) \\
3(2.59 \%) \\
22(18.97 \%)\end{array}$ \\
\hline Totals & 一 & 4,632 & 142 & 133 & 116 \\
\hline
\end{tabular}

'Since only anti-C $+C^{w}$ was available, the term ' $C$ antigen' includes both pure $C$ and the $C^{w}$ variant.

Rarer genotypes such as $\mathrm{CdE} / \mathrm{cde}\left(\mathbf{R}_{\mathbf{y}} \mathbf{r}\right)$ or $\mathrm{Cde} / \mathrm{cdE}\left(\mathbf{R}^{\prime} \mathbf{R}^{\prime \prime}\right)$ omitted.

Combining cDe, Ccde, and cdE.

Control series $2 /$ affected children-adjusted $x^{2}=10.83$, d.f. $=5,0.1>P>0.05$.

TABLE IV

RHESUS-D GROUP DISTRIBUTION

\begin{tabular}{lccc} 
Group & Control Series l & Control Series & No. of Affected Children \\
\hline Rh D +ve & $344(80 \cdot 56 \%)$ & $3,837(82 \cdot 84 \%)$ & $106(74 \cdot 65 \%)$ \\
Rh D - ve & $83(19 \cdot 44 \%)$ & $795(17 \cdot 16 \%)$ & $36(25 \cdot 35 \%)$ \\
Totals & 427 & 4,632 & 142
\end{tabular}

Control series 1/Control series 2-adjusted $\chi^{2}=1 \cdot 26$, d.f. $=1,0.3>P>0.2$.

Control series $1 /$ affected children-adjusted $x^{2}=1.91$, d.f. $=1,0.2>P>0.1$.

Control series $2 /$ affected children-adjusted $x^{2}=5.87$, d.f. $=1,0.02>P>0.01$.

donor control series by $\chi^{2}$ tests for independence of Rhesus phenotype and Perthes' disease, the three numerically smallest classes (cDe, Ccde, and cdE) were combined and the following result obtained:-

Control series $2 /$ affected children-adjusted $\chi^{2}=10 \cdot 83$, d.f. $=5,0.1>P>0.05$.

In this type of biological statistics it is customary to regard a significance level of 1 in 20 or less $(P \leqslant 0.05)$ as indicating that the figures under comparison are deviating significantly from each other due to influences other than chance. The value of the $\chi^{2}$ test for the affected children (10.83) does not quite reach the level of significance (for $\mathrm{P}=0.05$ with 5 d.f., $\chi^{2}=11.07$ ) but it approaches it sufficiently closely to warrant a closer study of the Rhesus phenotypes in these families. It is worth considering that the observed Rhesus phenotype distributions have resulted from one or other of the following influences operating on the families tested:-1 Chance, which is likely to be the responsible influence; 2 association between blood groups and disease (Fraser Roberts, 1959).

Inspection of Table III shows that there is an increase $(24.65 \%)$ over the control series $(16.23 \%)$ in the numbers of those found to be Rhesus negative, corresponding to the genotype cde/cde, among the affected children. In our earlier communication (Cameron and Izatt, 1960) we classified the series of 142 children with Perthes' disease into Rh Dpositive $(74.65 \%)$ or $R h$ D-negative $(25.35 \%)$, and compared the proportion of one to the other with that in a random series of 427 normal blood donors (control series 1, Table IV). By the time the testing of families had been completed a much larger control series of the Rhesus phenotypes of 4,632 random blood donors in the Glasgow and West of Scotland area was available (control series 2, Tables III and IV). The incidence of Rh D-negative persons among the 427 donors is $19.44 \%$ compared with $17 \cdot 16 \%$ in the larger series of 4,632 donors. One outcome of this variation in the incidence of $\mathrm{Rh} \mathrm{D}$-negative persons in the two control series is now demonstrated by the following results:-

Control series $1 /$ affected children-adjusted $x^{2}=1.91$, d.f. $=1,0 \cdot 2>P>0 \cdot 1$.

Control series 2 /affected children-adjusted $x^{2}=5.87$, d.f. $=1,0.02>\mathrm{P}>0.01$. 
By using the larger series 2 as controls, but not the smaller series 1 , the proportion of $\mathrm{Rh} \mathrm{D}$-positive to $\mathrm{Rh} D$-negative in the affected children can be seen to deviate apparently significantly at the 1 in 20 level from that of the random donor controls. The two sets of controls do not themselves differ significantly from each other, and can be accepted as random samples of different sizes from the same population (adjusted $\chi^{2}=1 \cdot 26$, d.f. $=1,0.3>P>0.2$ ). It is always advisable to use for a control series the largest which is available in order to minimize the effects of random sampling within the population. For this reason, control series 2 was used in all subsequent calculations.

A still closer inspection of Table III led us to test the data for association between Perthes' disease and the cc phenotype. Table V shows the Rhesus $\mathrm{C}$ and $\mathrm{c}$ group distributions. It should be noted particularly that the incidence of the homozygous cc phenotype is considerably higher in the affected children at the expense of the heterozygous $\mathrm{Cc}$ and homozygous $\mathrm{CC}$ phenotypes (adjusted $\chi^{2}=11 \cdot 3$, d.f. $=1, \mathrm{P}=0.0008$ ). This $\chi^{2}(\mathrm{P} \fallingdotseq 0.0008)$ was selected as the most significant of about $20 \chi^{2}$ tests which could reasonably have been carried out on Tables II and III. Such tests would have involved, for instance, the distribution among $\mathrm{C} / \mathrm{c}$ phenotypes, $\mathrm{D} / \mathrm{d}$ phenotypes, $\mathrm{E} / \mathrm{e}$ phenotypes, heterozygotes/homozygotes, and all $\mathrm{Rh}$ groups in the full Table III. The effects of chance deviations are obviously heightened by this selective procedure, and it is difficult to compensate for this effect. It might be reasonable, however, to take the significance level, $\mathrm{P}$, as $\mathrm{P} \fallingdotseq 0.02$ (i.e., $0.0008 \times 20$ ).

The evidence is sufficient to justify collecting further data in some other region to confirm the suggestion that there is an association between $\mathrm{cc}$ and Perthes' disease. Whether the excess of $\mathrm{cc}$ among affected children is due to chance or to association, some trend towards an increased incidence of
TABLE V

RHESUS C AND $C$ GROUP DISTRIBUTION

\begin{tabular}{|c|c|c|}
\hline Group & Control Series 2 & No. of Affected Children \\
\hline $\begin{array}{l}\mathrm{CC} \\
\mathrm{Cc} \\
\mathrm{cc}\end{array}$ & $\begin{array}{r}795(17 \cdot 16 \%) \\
2,354(50.82 \%) \\
1,483(32.02 \%)\end{array}$ & $\begin{array}{l}19(13.38 \%) \\
58(40.85 \%) \\
65(45.77 \%)\end{array}$ \\
\hline Total & 4,632 & 142 \\
\hline
\end{tabular}

On combining $C C$ and $C c$ and comparing with cc, adjusted $x^{2}=11 \cdot 3$, d.f. $=1, P \fallingdotseq 0.0008$.

c-containing phenotypes might also be expected among the parents. Such a trend, particularlyo among fathers, is noted in Table III.

Apparent association can be the result of strati-i fication within the general population, in which two strains can coexist. In one strain there can be a highw incidence of both Perthes' disease and the Rhesus-o negative phenotype, while the other could becharacterized by low incidences of both. Study of the blood groups of the families of affected children, especially their sibs, can be useful in differentiating between an association due to stratification and a relationship more basic or causal in nature. Within individual families stratification would produce nog effect on the expected blood group distributions Information was, therefore, compiled for Table $\mathrm{V} F$ from 109 families in which each parent had beent scored for the CC, Cc, or cc phenotype using anti- $\mathrm{C}_{\Omega}^{\mathbb{D}}$ $+\mathrm{C}^{\mathrm{w}}$ and anti-c. Thus the Cc genotypes of these 109 marriages could be determined without reference tọ their children's groups. These marriages produced 348 children of whom 109 have Perthes' disease anç 239 do not.

Three types of marriage $\mathrm{CC} \times \mathrm{CC}, \mathrm{CC} \times \mathrm{cc}$, and cc $\times$ cc yield children whose groups can only belong to a single class, $\mathrm{CC}, \mathrm{Cc}$, or cc respectively. $\mathrm{No}$. alternatives are possible, hence the 23 families of these mating types must be excluded from analysis

TABLE VI

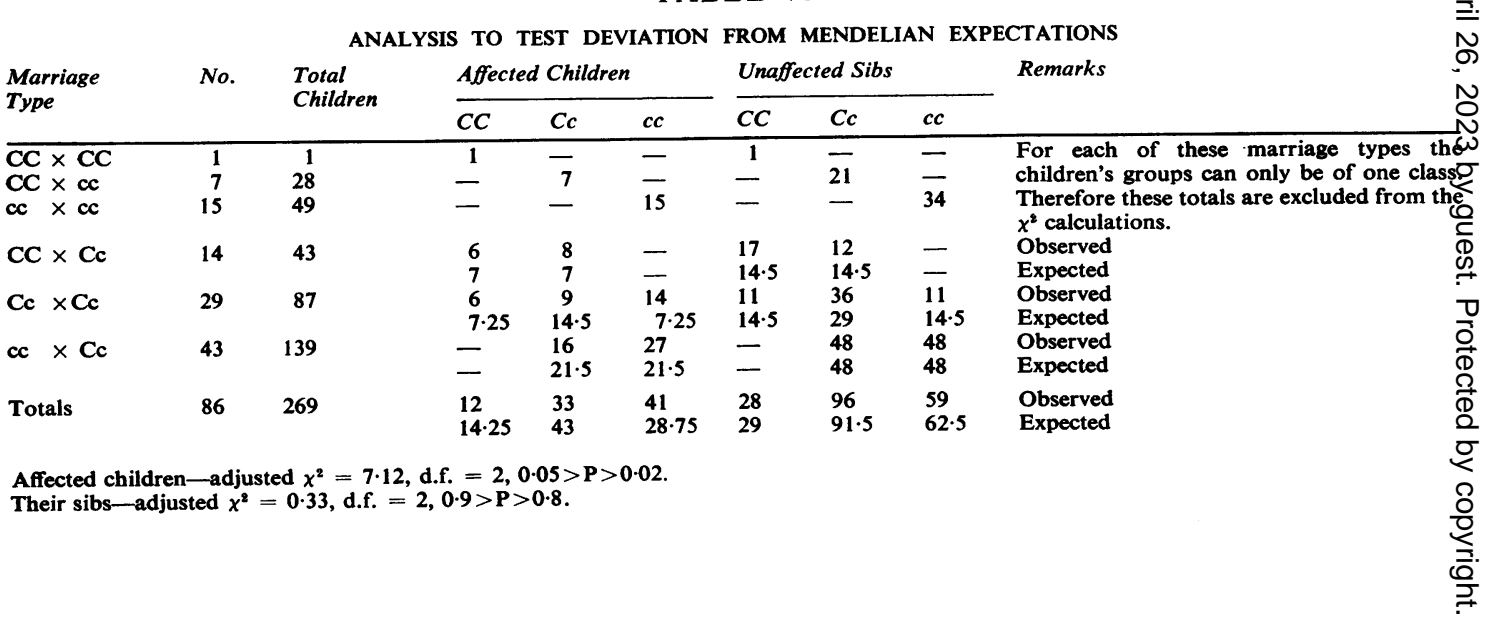


leaving 86 families to be considered further (Table VI).

Among the unaffected sibs the distribution of the Rhesus C-c groups deviates very little from that expected on the basis of Mendelian inheritance of the $\mathrm{C}$ and $\mathrm{c}$ factors (adjusted $\chi^{2}=0.33$, d.f. $=2$, $0.9>P>0.8$ ). However, there appears to be a significant excess of homozygous cc over heterozygous Cc among the affected children (adjusted $\chi^{2}=7 \cdot 12$, d.f. $=2,0.05>P>0.02$ ). The observed ratio of the $\mathrm{Cc} / \mathrm{cc}$ groups is $33 / 41$, but that expected is almost the reciprocal, $43 / 28 \cdot 75$. These findings are not independent of the earlier $\chi^{2}$ tests for association between Perthes' disease and the presence of the Rhesus $\mathrm{c}$ cr the absence of the $\mathrm{C}$ antigen but they do indicate that if the association is real and not due to chance it is also not due to stratification.

ANTIBODY SCREENING TESTS AT $37^{\circ} \mathrm{C}$. These were done on the affected children and their families.

Affected children No immune Rhesus or other antibodies could be detected in the sera of the children affected by Perthes' disease.

Mothers of affected children The sera of five Rhesus D-negative mothers were found to contain Rhesus antibodies. Two were examples of saline agglutinating anti-D, and three were albumin agglutinating anti-D sera. The antigenic stimuli leading to the production of these maternal antibodies appear from information given to us to have been Rhesus $\mathrm{D}$ incompatible pregnancies, rather than incompatible blood transfusions.

Fathers of affected children In one paternal serum an anti-C+D was detected. This Rhesus D-negative man apparently acquired the antibody over eight years ago as the result of multiple transfusions following gastrointestinal haemorrhage.

It was noted during the reading of $\mathrm{ABO}$ grouping tests that two paternal sera contained irregular antibodies active at room temperature. In both instances these were identified as anti- $A_{1}$ occurring naturally in a group $\mathrm{A}_{2} \mathrm{~B}$ and a group $\mathrm{A}_{2}$ individual.

Sibs of affected children No serum could be shown to contain immune Rhesus or other antibodies.

COMPATIBILITY TESTING The aim of this section of the investigation was to see if the development of Perthes' disease might be a consequence late in childhood of mother/child blood group incompatibility. Many of the mothers had themselves claimed that their child with Perthes' disease was jaundiced at birth. Our findings have not borne out the idea of there being an excess in the numbers of mothers, who, having children suffering from Perthes' disease, also have blood group antibodies in their sera towards the red cell antigens of their affected children.

Compatibility tests between maternal serum and the red cells of husband and children only detected those incompatibilities of the ABO and Rhesus systems which were to be anticipated from knowledge of the ABO and Rhesus groups of the individuals concerned in conjunction with the results of the antibody screening tests on the maternal serum.

The ABO group distributions in this series of. children with Perthes' disease, and in their parents, have already been shown not to differ significantly from those of a random series of donor controls (Table II). It would appear too that the ABO groups are exerting no special selective effects in these families, as measured by the observed numbers of ABO heterospecific pregnancies. Of the children affected with Perthes' disease, $16.5 \%$ have ABO groups incompatible with maternal anti-A and/or anti-B. Levine (1958) quotes figures in the range $18 \%$ to $23 \%$ as representative of the population at random.

For the 109 families of Table VI in which both parents have been grouped it can be calculated, using the Rhesus D group distributions of Table IV and assuming random marriage, that 17 to 18 of these parental marriages should belong to the class of $\mathrm{Rh} \mathrm{D}$-positive husband $\times \mathrm{Rh} \mathrm{D}$-negative wife. In fact 19 such marriages were observed, with the wife developing anti-D in three instances in response to Rhesus D incompatible pregnancies. This frequency of 1 in 6 for the development of anti-D in the serum of the Rhesus-negative wife of a Rhesus-positive husband is greater than the published incidence of 1 in 17 (Stratton and Renton, 1958). No particular emphasis should, however, be placed on this fact owing to the small numbers involved from the present series. There were two further families in which the wife developed anti-D, but as it was impossible to get permission to group the husbands, they were not included in these last calculations.

Of the 86 families classified in the lower half of Table VI, seven involve marriage between a heterozygous Cc husband, who is $\mathrm{Rh} \mathrm{D}$-positive, and a homozygous cc wife, who is $\mathrm{Rh} \mathrm{D}$-negative and potentially capable of developing anti-D in response to Rhesus D incompatible pregnancies, though only two have done so (Nos. 38 and 77). Of their children with Perthes' disease, three are heterozygous $\mathrm{Cc}$ and $\mathrm{Rh} D$-positive, while four are homozygous cc and $R h$ $D$-negative. Thus the remaining 79 families, in which the mothers are all $\mathrm{Rh} \mathrm{D}$-positive with no detectable $R$ hesus antibodies in their sera, must be largely responsible for the observed excess of cc children affected by Perthes' disease. 
It is instructive to note the following details regarding the five children who developed Perthes' disease, and whose mothers have circulating Rhesus antibodies. Families 38, 50, and 77 are included in the 109 analysed in Tables V and VI, but as already explained families 119 and 123 are omitted. No. 38, third in sibship, Rh D-positive, was jaundiced at birth but not transfused. No. 50, first in sibship, $\mathrm{Rh}$ D-positive, did not have haemolytic disease of the newborn. No. 77, first in sibship, Rh D-negative, did not have haemolytic disease of the newborn. No. 119, first in sibship, Rh D-positive, did not have haemolytic disease of the newborn. No. 123, thirteenth in sibship, Rh D-positive, jaundiced at birth, was not transfused.

This is a final pointer that maternal Rhesus antibodies are not a direct stimulus to the development of Perthes' disease. Only two of the above five children exhibited signs of blood destruction by maternal antibody (Nos. 38 and 123) at birth, and yet all five have $R h$ D-positive sibs who have suffered from haemolytic disease of the newborn but to date have failed to develop Perthes' disease. Thus it would appear that the origin of Perthes' disease in the affected child is independent of an earlier haemolytic disease of the newborn due to maternal Rhesus antibodies.

A condition giving an almost identical clinical picture to that of Perthes' disease is found in association with sickle cell disease (Golding,
MacIver, and Went, 1959). It is interesting to note, according to Race and Sanger (1958), that some years ago the gene for sickle red cells was thought tow be linked to the $\mathrm{MN}$ genes but this was later showno not to be the case.

We wish to thank Professor R. Barnes and his staff at theo Western Infirmary, particularly Mr. N. J. Blockey, together with the surgeons at the Royal Hospital for Sickes Children, Glasgow, for permission to study their cases. $\overrightarrow{0}$ We also thank Dr. J. Wallace, Glasgow and West ofScotland Regional Blood Transfusion Service, for pro- $\vec{\omega}$ viding facilities for the blood grouping studies, and for his? advice and criticism in the preparation of this paper. We are also indebted to Dr. J. H. Renwick, Department of Genetics, University of Glasgow, for his assistance with the genetical and statistical aspects of our investigation, and finally to Dr. J. A. Fraser Roberts for his earlier assistance.

\section{REFERENCES}

Cameron, J. M., and Izatt, M. M. (1960). Scot. med. J., 5, 148.

Goff, C. W., Shutkin, N. M., and Hersey, M. R. (1954). Legg-Calvé Perthes Syndrome, and Related Osteochondroses of Youth.? Thomas, Springfield, Illinois.

Golding, J. S. R., Maclver, J. E., and Went, L. N. (1959). J. Bone J $\overrightarrow{\mathrm{e}}$ Surg., 41B, 711

Jonsäter, S. (1953). Acta orthop. scand., Suppl. 12.

Levine, P. (1958). Hum. Biol., 30, 14

Race, R. R., and Sanger, R. (1958). Blood Groups in Man, 3rd ed Blackwell, Oxford.

Roberts, J. A. Fraser (1959). Brit. med. Bull., 15, 129.

Stratton, F., and Renton, P. H. (1958). Practical Blood Grouping, 1s ed., p. 14. Blackwell, Oxford.

Wansbrough, R. M., Carrie, A. W., Walker, N. F., and Ruckerbauer G. (1959). J. Bone Jt Surg., 41A, 135. 